\title{
Effects of Cryotherapy and Static Stretching Together and Static Stretching Alone For Improving Plantar Flexors Extensibility
}

\author{
Mrs. Shabana Khan ${ }^{1}$, Sharick Samsi ${ }^{2}$, Dr Samiha Abdelkader ${ }^{3}$ \\ ${ }^{1}$ MPT (Sports Medicine) Researcher, College of Applied Sciences Dept. of Rehabilitation King Saud \\ UniversityP.O. Box - 10219 Riyadh, Kingdom of Saudi Arabia, \\ ${ }^{2}$ MPT (Ortho) Lecturer Raj Nursing and Paramedical College Gorakhpur, U.P. \\ ${ }^{3}$ PhD in (Kinesiology) Assistant Professor, College of Applied Sciences Dept. of Rehabilitation \\ King Saud University
}

\begin{abstract}
Study objective: To know the effects of cold applications during static stretching on plantar flexors extensibility. Design: Pre test and post test control group.

Method and measurements: 30 volunteers of 18-30 years participated in study. Subjects were randomly and equally assigned to Ice pack and static stretching (group A) and static stretching (group B). Subjects in each group were given stretching to plantar flexors with $1 / 3^{\text {rd }}$ of body weight once a day for 5 days a week for three weeks. ROM was measured before and after treatment session on the day of treatment and the end of each week. Results: Means and S.D of active dorsiflexion ROM after 3 weeks were 16.10 2.80 for group A. ANOVA demonstrates that there was a significant difference in pre and post intervention ADFROM in both groups $(P$ $<0.05)$. When both group were compared the difference was statistically significant $(P<0.05)$.

Conclusion: Both groups in the study showed increase in the extensibility of plantar flexors, resulting in increase in ADFROM. Both the cryotherapy and stretching significantly improved ROM; however, there was no difference between two treatment conditions.
\end{abstract}

Key words: Cryotherapy, flexibility, ROM, static stretching.

\section{Introduction:}

Flexibility training has its roots in 1900's due to increased orthopedic cases from World war I. Public attention was heightened with the 1950's publication by Kraus and Hirschland. Those who now proclaim flexibility training include coaches, personal trainers, fitness instructors, medical doctors, physical therapists, etc $^{1}$.

Planter Flexors play important role in gait cycle and postural control. Lack of their extensibility cause decreases in ankle dorsiflexion, and contribute to Achilles tendinitis ${ }^{3}$, shin splints, plantar fasciitis, muscle strain and joint sprain $^{2,3}$.

Increased tightness of gastrocnemius was found to be risk factor for Achilles tendinitis ${ }^{4}$. Mc Kay et al found that those athletes who did not stretch during warm-up were at significantly increased risk of injury compared with those who did stretch ${ }^{5}$.

Physiotherapists use wide variety of treatment techniques to improve flexibility, decrease joint stiffness, prevent deformity and dysfunction.It includes - stretching, moist heat packs, cold packs, US therapy, CPM, active and passive exercises, etc ${ }^{3,6}$.

Static stretching is most commonly performed to increase muscle length ${ }^{7-8 .}$

Cold are widely used in clinical application involving physiotherapy ${ }^{9}$. The principle methods of cold modalities to improve efficacy of stretching are by reducing muscle pain and muscle guarding ${ }^{10}$.

Cryotherapy enhances joint mobility by providing pain relief ${ }^{11}$, inhibiting muscle spasm and reducing muscle tension $^{12}$.

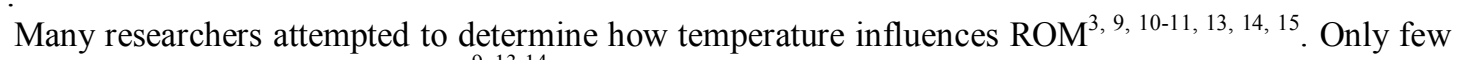
investigated the effect of cooling on $\mathrm{ROM}^{9,13-14}$.

However, little scientific evidence exists regarding effectiveness of application of cold and static stretching for limited ankle dorsiflexion range.

Purpose of this study was to investigate the efficacy of Cryostretch for increasing plantar flexors extensibility. This study compared the effect of ice pack during static stretching on plantar flexors extensibility. 


\section{Subjects}

\section{Material And Method}

30 healthy students $(\mathrm{M}=15 ; \mathrm{F}=15$; Age-22.96 \pm 2.34 years; Height- $64.43 \pm 8.36 \mathrm{~cm}$; Weight- $55.93 \pm$ $6.93 \mathrm{~kg}$ ) completed study. The study design was approved by research committee of Jamia Hamdard and was conducted at Majeedia Hospital, Delhi. The inclusion criteria was inability to achieve 20 degrees of active dorsiflexion $\mathrm{ROM}^{5}$. We excluded subjects having, recent injury or $\mathrm{H} / \mathrm{O}$ ankle injury, neuromuscular disorders (head injury, polio, stroke etc.), impaired sensation, musculoskeletal disorders involving trunk, spine and lower extremities, hyper mobility skin disease, open sores and any circulatory problem, subjects allergic to ice or hot packs, sports persons involved in any flexibility or strength training for calf muscle and subjects under medication (muscle relaxants) ${ }^{2}$. Subjects were informed about purpose and procedure of study and written consent was taken prior to participation. They were randomly assigned into group A (IP+SS) and group B (SS alone), each consisting of 15 subjects.

\section{$\underline{\text { Design }}$}

Study utilized pre \& post test control group design.

\section{Equipments and measuring tools}

Equipments- Ice pack, stop clock, permanent marker, straps, couch, pulley, metal cable and weights

Measuring tools- Transparent (plastic) Goniometer, weighing machine and measuring tape.

\section{Procedure}

30 volunteers of 18-30 years participated in study. Subjects were randomly assigned to Ice pack and static stretching (group A) and static stretching alone (group B), each consisting of 15 subjects. Subjects in each group were given 10 minutes to the right leg plantar flexors stretching with $1 / 3^{\text {rd }}$ of body weight once a day for 5 days a week for three weeks. ROM was measured on day of treatment and end of each week. Subjects were instructed to report at same time every day for treatment ${ }^{3}$. A standard tape measurement was used to ensure that subjects were positioned prone on the testing couch with their lateral maleolus 9" beyond the tables' edge. All the subjects were instructed to wear shorts and secured to table with waist and knee straps. Their right leg (dominant) was used throughout the study ${ }^{16}$.

The group B received 10-minute static stretch lying prone on table with $1 / 3^{\text {rd }}$ of body weight .Group A received ice pack for 10 minutes during static stretch with $1 / 3^{\text {rd }}$ of the body weight.

During every session, weight was adjusted in $2-\mathrm{kg}$ increment until $1 / 3^{\text {rd }}$ of the subjects' body weight ${ }^{10}$.

For goniometric measurement, stationary arm was placed along the long axis of fibula by using marks on the fibular head and lateral maleolus. Moving arm of the Goniometer was placed parallel to the lateral border of the foot by using marks on base of the head of the fifth metatarsal. The zero position of dorsiflexion was defined as 90 degree angle between long axis of the fibula and lateral border of the foot. All the measurements were recorded immediately as the subjects achieved maximum $\mathrm{ADROM}^{16}$.

\section{Data Analysis}

Data was analysed using statistical tests which were performed using SPSS 15.00 software package. A 2 factor (group and time) ANOVA with repeated measures on one factor time was performed.

\section{Findings}

In this study we have taken 30 subjects with a mean age of $22.96 \pm 2.34$ years, average weight $55.93 \pm 6.93$ kilograms and with mean height of $164.43 \pm 8.36$ centimeters (table1).

\begin{tabular}{|c|c|c|l|l|}
\hline & $\begin{array}{c}\text { Group A } \\
\text { Mean } \pm \text { S.D } \\
\mathrm{N}=15\end{array}$ & $\begin{array}{c}\text { Group B } \\
\text { Mean } \pm \text { S.D } \\
\mathrm{N}=15\end{array}$ & F & \multicolumn{2}{|c|}{$\begin{array}{c}\text { PNOVA } \\
\text { Age (years) }\end{array}$} & $23.10 \pm 2.64$ & $22.50 \pm 2.27$ & 0.301 & 0.743 \\
\hline Height (cms) & $164.10 \pm 7.65$ & $164.30 \pm 9.73$ & 0.023 & 0.977 \\
\hline $\begin{array}{c}\text { Weight } \\
\text { (kgs) }\end{array}$ & $54.70 \pm 7.16$ & $57.60 \pm 6.22$ & 0.448 & 0.643 \\
\hline
\end{tabular}

Table 1: Mean and standard deviations of age, height \& weight between group $A$ and group $B$.

\section{Dorsiflexion Range}

Active dorsiflexion range of motion (ADFROM) was the dependent variable. Mean and SD of ADROM after 3 weeks were $22.50 \pm 2.50$ for group A and $16.10 \pm 2.80$ for group B. 
Within group analysis of ADFROM (Table 2, Table 3)

Both the groups had significant difference in pretest and post test values as $\mathrm{p}$ and $\mathrm{F}$ values for groups $\mathrm{A}$, and $\mathrm{B}$ were $\mathrm{p}=0.000, \mathrm{~F}=509.53$ and $\mathrm{p}=0.000, \mathrm{~F}=312.11$ respectively. ANOVA shows that there was statistically significant improvement in the ADFROM in both the groups $(\mathrm{p}<0.05)$.

\begin{tabular}{|l|c|c|c|c|c|c|c|}
\hline & & PRETEST & PTWK O & PTWK 1 & PTWK 2 & PTWK 3 & \multicolumn{2}{|c|}{ ANOVA } \\
\cline { 6 - 8 } Groups & Mean \pm S.D & Mean \pm S.D & Mean \pm S.D & Mean \pm S.D & Mean \pm S.D & F value & P value \\
\hline Group A & $8.90 \pm 3.69$ & $11.00 \pm 3.68$ & $14.60 \pm 3.06$ & $19.10 \pm 2.37$ & $22.50 \pm 2.54$ & 509.53 & 0.000 \\
\hline Group B & $8.20 \pm 3.35$ & $9.50 \pm 3.27$ & $11.0 \pm 2.98$ & $13.40 \pm 2.95$ & $16.10 \pm 2.80$ & 312.11 & 0.000 \\
\hline
\end{tabular}

Table2: Within group comparison of ADFROM (degrees). Mean and SD of pretest and post test week $0,1,2,3$ values were used for comparison.

\begin{tabular}{|c|c|c|}
\hline Variables & Group A & Group B \\
\hline 1 vs. 2 & 0.000 & 0.000 \\
\hline 1 vs. 3 & 0.000 & 0.000 \\
\hline 1 vs. 4 & 0.000 & 0.000 \\
\hline 1 vs. 5 & 0.000 & 0.000 \\
\hline 2 vs. 3 & 0.001 & 0.003 \\
\hline 2 vs. 4 & $\mathbf{0 . 0 0 0}$ & 0.000 \\
\hline 2 vs. 5 & 0.000 & 0.000 \\
\hline 3 vs. 4 & 0.000 & 0.000 \\
\hline 3 vs. 5 & 0.000 & 0.000 \\
\hline 4 vs. 5 & 0.000 & 0.000 \\
\hline
\end{tabular}

Table 3: Post hoc analysis for within group comparison of ADFROM (degrees). $1=$ pretest; $2=$ post test week 0 ; $3=$ post test week $1 ; 4=$ post test week2; $5=$ post test week3.

\section{Between group analysis of ADFROM (Table 4)}

Dorsiflexion ranges between both groups were compared at Pretest, PTW0, PTW1, PTW2 and PTW3. Statistically significant difference was found between group A and group $B(p=0.000)$ at the end of third week $(\mathrm{p}>0.05)$ a statistically significant difference was reported $(\mathrm{p}<0.05)$.

\begin{tabular}{|c|c|c|c|c|c|}
\hline \multirow{2}{*}{ Variables } & \multirow{2}{*}{$\begin{array}{c}\text { Group A } \\
\text { Mean } \pm \text { S.D } \\
\mathrm{N}=15\end{array}$} & $\begin{array}{c}\text { Group B Mean } \pm \text { S.D } \\
\mathrm{N}=15\end{array}$ & \multicolumn{2}{|c|}{ ANOVA } & $\begin{array}{c}\text { Post hoc } \\
\text { analvsis }\end{array}$ \\
\cline { 4 - 6 } & & & F value & P value & A vs.B \\
\hline Pretest & $8.90 \pm 3.69$ & $8.20 \pm 3.35$ & 1.472 & 0.247 & 1.000 \\
\hline PTWK 0 & $11.00 \pm 3.68$ & $9.50 \pm 3.27$ & 1.792 & 0.186 & 1.000 \\
\hline PTWK 1 & $14.60 \pm 3.06$ & $11.0 \pm 2.98$ & 5.799 & 0.008 & 0.026 \\
\hline PTWK 2 & $19.10 \pm 2.37$ & $13.40 \pm 2.95$ & 12.55 & 0.000 & 0.000 \\
\hline PTWK3 & $22.50 \pm 2.54$ & $16.10 \pm 2.80$ & 16.01 & 0.000 & 0.000 \\
\hline
\end{tabular}

Table 4: Between group comparison of ADFROM (degrees). Mean and SD of pretest and post test week 0, 1, 2, 3 values were used for comparison.

\section{Discussion}

This study documented effects of cold modalities in conjunction with static stretching for improvement of plantar flexor extensibility limited by soft tissue tightness in healthy subjects.

The main result of this study was that both the interventions (SS+IP and SS alone) were effective in improving plantar flexors extensibility.

Within group analysis showed that ADFROM improved in both the groups significantly $(p=0.000$, meaning that both the interventions were effective in improving plantar flexors extensibility.

The findings of this study are consistent with the findings of many researchers $3,7,10,15$

The findings of this study are consistent with the findings of Robert et $\mathrm{al}^{12}$.

Cryotherapy has been found to affect the viscoelastic properties of muscle tendon unit ${ }^{17}$ and muscle's myostatic reflex ${ }^{6}$.

Cryotherapy allows muscle to relax and be stretched more fully during stretching. According to William Prentice ${ }^{17}$ cryotherapy increases the muscles viscosity and hence slows down the muscles ability to contract and spasm. Also cooling of stretched muscle has been found to cause depression of stretch reflex ${ }^{6,11,18}$. 
The postulated mechanisms for this effect are that the cryotherapy causes direct sensory stimulation of primary and secondary muscle spindle afferent fibers and thus indirect reflex inhibition which decreases $\gamma$-activity and lowers muscle's threshold to interfere in muscle excitability ${ }^{19}$.

Bell et $\mathrm{al}^{6}$ found that SS combined with cryotherapy showed reduced T- reflex. According to Knight ${ }^{18}$ the ice treatment if combined with SS, subjects may find it easier to endure the mild discomfort commonly felt at the terminal position of stretch allowing the muscle to be stretched more fully.

The results of this study supported YH $\operatorname{Lin}^{9}$ who stated that application of cold combined with SS achieved a significant increment of ROM in clinical settings.

The findings of this study are in accordance with Minton ${ }^{19}$ who reported that cryotherapy significantly improved immediate ROM.

Our results are in contrary to Gary et $\mathrm{al}^{14}$. Differences in protocol, subjects, treatments and data analysis may be partly responsible.

Present study also included equal number of males and females to demonstrate difference in flexibility between them. However, there was no significant difference in terms of flexibility in males and females in this study. These results are in contrast with Youdas ${ }^{20}$ et al who reported that there is statistically significant effect of gender on HML (hamstring muscle length) with women having more HML than their male counterparts.

\section{Conclusion}

Both the groups showed increase in extensibility of plantar flexors, resulting in increase in ADROM. Both the cryotherapy and Streathing significantly improved ROM of plantar flexors.

These results suggest that an athlete may select cryotherapy modalities for the purpose of optimizing the effects of stretching. However the choice should depend on condition of the joint and surrounding tissues as well as individual preference for ice. This study will allow clinicians the choice of cost effective treatment alternative. Moreover ice packs are easily available.

\section{Interest Of Conflict}

- $\quad$ Limited and small sample size.

- Lack of measuring thickness of subcutaneous fat around the calf muscle which could have produced difference in intramuscular temperature.

- These results cannot be applied to older or injured subjects without further research.

- $\quad$ Lasting effects of increased flexibility was also not measured.

- $\quad$ Room temperature was not regulated.

\section{References-}

[1]. Kravitz L Heyward V. Flexibility Training: Fitness Management. 1995; 11(2): 32-33, 36-38.

[2]. Kisner C, Colby LA. Therapeutic Exercise Foundation and Techniques. $3^{\text {rd }}$ Edition, F A Davis: Philadelphia. 24-25, 221, 157, 482483.

[3]. Claudia A Knight, Carrie R Rutledge, Michael E Cox, Martha Acosta And Susan J Hall. Effect of Superficial Heat, Deep Heat And Active Exercise Warm-Up On The Extensibility Of The Plantar Flexors. Phys Ther. 2001; 81(6): 1206-1214.

[4]. D F Murphy, D A Connolly, B D Beynnon. Risk Factors For Lower Extremity Injury: A Review Of The Literature. Br J Sports Med. 2003; 37: 13-29.

[5]. Mc Kay G D, Goldie P A, Payne WR Et Al. Ankle Injuries In Basketball: Injury Rate And Risk Factors. Br J Sports Med. 2001; 35 : 103-108.

[6]. Kathleen R Bell, Justus F Lehmann. Effect of Cooling On H- And T- Reflexes In Normal Subjects. Arch Phys Med Rehabil. 1987; 68: 490-493.

[7]. Michael K Sullivan, Joseph J Dejulia and Teddy W Worrell. Effect of Pevic Position And Stretching Method On Hamstring Muscle Flexibility. Med Sci Sports Exerc. 1992; 24(12): 1383-1389.

[8]. Craig A Smith. The Warm-Up Procedure: To Stretch Or Not To Stretch. A Brief Review. J Orthop Sports Phys Ther. 1994; 19(1): 12-17.

[9]. Y H Lin. Effect of Thermal Therapy In Improving The Passive Range Of Knee Motion: Comparison Of Cold And Superficial Heat Applications. Clin Rehabil. 2003; 17: 618-623.

[10]. Steven E Peres, David O Draper, Kenneth L Knight, Mark D Ricard. Pulsed Shortwave Diathermy And Prolonged Long Duration Stretching Increase Dorsiflexion Range Of Motion More Than Identical Stretching Without Diathermy. J Ath Train. 2002; 37(1): 4350 .

[11]. Bugaj R. The Cooling, Analgesic and Rawarming Effects Of Ice Massage on Localized Skin. Phys Ther. 1975; 55(1): 11-19.

[12]. Robert Price, Justus F Lehmann, Sherlyn Boswell-Bessette, Anne Buleign, Bashara J Delateur. Influence of Cryotherapy on Spasticity At The Human Ankle. Arch Phys Med Rehab. 1993; 74: 300-304.

[13]. Gary Lentell, Thomas Hetherington, Jeff Eagan, Mark Morgan. The Use of Thermal Agents To Influence The Effectiveness of A Low-Load Prolonged Stretch. J Orthop Sports Phys Ther. 1992; 16(5): 200-207.

[14]. Gary R Brodowicz, Robert Welsh, James Wallis. Comparison of Stretching With Ice, Stretching With Heat, Or Stretching Alone On Hamstring Flexibility. $J$ Ath Train. 1996; 31(4): 324-327.

[15]. David O Draper, Jennifer L Castro, Brent F, Shane Schulthies, Dennis Eggett. Shortwave Diathermy And Prolonged Stretching Increase Hamstring Flexibility More Than Prolonged Stretching Alone. J Ortho Sports Phys Ther. 2004; 34: 13-20.

[16]. Kenneth C Wessling, Dawn A Devane, Cynthia R Hylton. Effects Of Static Stretch Versus Static Stretch And Ultrasound Combined On Triceps Surae Muscle Extensibility In Healthy Women. Phys Ther. 1987; 5: 674-679. 
[17]. Prentice W E. Therapeutic Modalities in sports medicine. St. Louis. Mo. Times mirror/mosby.1990:90-92.

[18]. Kenneth L knight. Cryotherapy In Sports Injuries Management. $1^{\text {st }}$ Edition. Human Kinetics, USA. 1995; 127-147, 171

[19]. Minton J. A Comparison Of Thermotherapy And Cryotherapy In Enhancing Spine Extended Leg, Hip Flexion. J Ath Train. 1993; 28(2): 172-176

[20]. James W Youdas, David A Krause, John H Hollman, William S Harmsen, Edward Laskowsi.The Influence Of Gender and Age on Hamstring

[21]. Muscle Length In Healthy Adults. J Orthop Sports Phys Ther. 2005; 35: 246-252. 